\title{
Virtual Reality Simulation: An Innovative Teaching Tool for Dietetics Experiential Education
}

\author{
Anne Davis* \\ University of Saint Joseph, 1678 Asylum Ave., West Hartford, CT 06117, USA
}

\begin{abstract}
This paper investigates the role of virtual reality and web technologies in the field of dietetics education. Within this frame, special emphasis is given on the building of web-based virtual learning environments so as to successfully fulfill their educational objectives. In particular, basic pedagogical methods are studied, focusing mainly on the efficient preparation, approach and presentation of learning content, and specific designing rules are presented considering the hypermedia, virtual and educational nature of this kind of applications. The paper also aims to highlight the educational benefits arising from the use of virtual reality technology in dietetics and study the emerging area of webbased dietetic simulations. Virtual reality simulation allows the visualization of data in three dimensions and provides interactive functionalities that reinforce the feeling of immersion into a computer-generated virtual world. Finally, the innovative virtual reality environment for dietetics education pedagogy and development is demonstrated.
\end{abstract}

Keywords: dietetics education, simulation, virtual reality.

\section{INTRODUCTION}

\section{The Current Dietetics Education Environment}

Dietetics education providers are seeking novel learning strategies that will support the ability of the student to learn complex skills in a safe environment. Much like other disciplines, the dietetics field continues to increase in complexity of problem solving and critical thinking. Gaddis defined VR as "a computer-generated simulation of the real or imaginedenvironment or world" [1]. Simply put, simulation is the act or process of modeling, imitation or representation of a potential situation [2]. Simulation education serves as a bridge between classroom learning and real-life clinical experience" [2].

Medicine has undergone major changes over the last 50 years. Today it is recognized that medical knowledge doubles every 6-8 years, with new medical procedures emerging everyday" [3]. Multiple choice tests and oral exams have been the traditional methods to assess knowledge and ability for generations. However, these methods are less than optimal for evaluating problemsolving and critical thinking skills [4]. Health-care professional education both present and future, is largely mired in the 100-year-old apprenticeship model best exemplified by the phase "see one, do one, teach one." Apart from the limited moments of real apprenticeship, for years lectures and films have formed the basis of health-care training [5].

\footnotetext{
*Address correspondence to these authors at the University of Saint Joseph, 1678 Asylum Ave., West Hartford, CT 06117, China;

E-mail: adavis@usj.edu
}

With the rapid growth oftechnology, medicine and science, acquisition of knowledge is no longer sufficient. Higher level skills such as effective communication, critical thinking, cooperative work and use of life-long learning resources all involve competence [6]. Raidl and colleagues demonstrated a decade ago that computer-based simulation enhanced clinical reasoning skills in undergraduate dietetic students [7]. There are several different types of simulations: live, virtual reality, and computer-based, standardized patients, partial task trainers, full-scale simulation, instructor-driven, model-driven simulators, physical vs. psychological and computerized manikins (low, mid, highfidelity) [8]. "Fidelity" is used to describe reality of the experience [9]. Combinations of simulations are used to evaluate the learning problem from various aspects.Virtual reality (VR) represents a promising area with high potential of enhancing and modifying the learning experience: virtual environments (VEs) can provide a rich, interactive, engaging educational context, supporting experiential learning [3].

Alternative Clinical Education (ACE) defines simulation as the artificial representation of a real world process to achieve educational goals via experiential learning [1]. Virtual reality simulation dietetic education may be used to develop experiential skill in a multitude of settings such as hospitals, clinics, private practice, food service business and management, military, public health departments and more.Types of simulation include games as classroom scenarios, case studies (book or computer based), lab values as in using human or animal tissue, procedural tasks vs. complex clinical responses, simulated patients for role playing; volunteers and actors, computer assisted virtual reality simulators,mannequins and task trainers and mock clinic and hospital facilities [4]. 
Virtual reality simulation is the use of 3-dimensional (3D) objects and environments to create immersive and engaging learning experiences. The principle of virtual reality simulation education is for the educator to impart, practice and check a student's knowledge using interactive scenarios and environments to reflect real-life situations [4]. The rationale for developing and implementing virtual reality simulation with avatars as a teaching technique in dietetics is to facilitate dietetic students to explore and manipulate computer-generated, 3-D, multimedia environments in real time. Virtual reality simulation is a one of the newer technological tools entering the clinical education environment.

One of the many benefits of virtual reality simulation with avatars is that it helps meet the demand for clinical placement sites, introduce new experiential environments difficult to access in person and embraces a new way of thinking about education. In the postsecondary health care field, simulation may be used as a teaching resource to reduce pressure on limited clinical sites and preceptors. Other benefits to using virtual reality simulation include increasing confidence of trainees from more and safe opportunities to practice skills and adding rigor to the credentialing and preceptor process. The use of virtual environments, such as 3-D immersion, multiple perspectives and multisensory cues offer a number of potential benefits to dietetics education and training such as experiential and active learning, visualization, learning in contexts impossible or difficult to experience in real life, motivation enhancement, collaboration fostering and adaptability [11]. This paper has the main aim of discussing the rationale and main benefits for the use of VR in dietetics education and training.

\section{VIRTUAL REALITY SIMULATION WITH AVATARS}

Avatars are 3-D'real life' individuals (e.g., student, dietetic intern,instructor dietitian, patient, nurse, pharmacist, physician and other hospital personnel) within the virtual hospital environment that are operated by students and lead by the instructor. Patient avatarshave visual signs of malnutrition (muscle wasting, loss of fat pads, skin rash, hair loss, vitamin deficiencies or wounds for the student dietitian avatar to assess, palpate and measure) in specific modules. Avatars' voices are adept to demonstrate body language and cultural diversity which enable learners to engage in simulation role-play with virtual patients and team members, providing a controlled, measurable and repeatable learning process. Students can choose and operate their own avatar in the professional setting to practice tasks and interact with a variety of patients and other health professionals. This teaching technique is an excellent forum for students to learn and practice how to interact, learn and work in an interdisciplinary fashion successfully.

Virtual reality simulation with avatars immerses the student dietitian into realistic clinical nutrition experiences without risk to patients and other learners. Learners are able to safely "fail" and learn from such failure in a way that would be inappropriate in a clinical setting [5]. Learners can be exposed to clinical opportunities/presentations they would rarely experience, and events can be scripted and practiced.
Scenarios can be designed with increasing complexity and introduced in a controlled way. This educational technique allows for practicing and repeating skills and activities in support of individual student needs [5].

\section{DIETETICS APPLICATION}

Web-based virtual environments are presented on an ordinary computer screen and are usually explored by keyboard, mouse, wand, joystick, or touchscreen.Computerbased simulations have been employed as tools in contemporary problem-based learning approaches, particularly in the development of skills such as clinical decision-making, inter-disciplinary team work and even management experiential training via immersion for other disciplines. Simulation continues to expand rapidly and has been an effective teaching toolaiding students to be better prepared and are more confident for clinical and community placements following simulation experiences.

Besides grade point average, pre-dietetic internship workplace experience and service learninghave become significant factorsin the dietetic internship application appraisal process. There is competition for limited available facilities for training and many facilities are paid to allow students to train on their sites so undergraduate students are at a disadvantage to find experiential education. The use of VR simulation is ideal to begin safe skill building and dietetics applications.Additionally, many dietetic internships do not have access to one or more central dietetic areas of supervised practice such as a children's hospital or dialysis center. VR simulationmay serve as virtual training environments for these absent training sites.

Additionally, VR simulation targets the specific area thereby allowing learners to draw on their own previous experience and experiences of others in group as a resource for learning dietetic skills (Table 1).

Table 1. VR simulation skills and teaching techniques in dietetics[adapted from reference 9]..

- Clinical Evaluations

- Health Assessment and Interviewing Skills

- Patient Education Strategies

- Communication and Ethical Dilemma Skills

- Team Collaboration Skills

- Inter-Professional Education

- Decision Making Skills

Some literature condemns lecture-based education as inefficient and ineffective in changing learned behaviors. It is said that lectures are inefficient because students cannot ask enough questions to meet their needs and ineffective because lectures do not commonly alter performance [1]. Student presence facilitates immediate contact with the instructor and debriefing for feedback. Afterward the student may practiceat home via computer for additional training. Students need the immediate feedback through the debriefing process in order to further develop and validate professional behavior and skill impression. The computer 
simulates an immersion into a hospital environment to include sounds, lights, equipment, measurement tools, furniture, health professionals, procedures, patients, electronic health record, wheelchairs, hospital supplies and more fixtures and attributes.

VR simulation both replaces and supplements educational activities for the Didactic Program in Dietetics (DPD) student, dietetic intern, graduate student and registered dietitian receiving continuing education training via providingadditional and new opportunities for clinical experience andskill building. Examples of how these new opportunities for clinical experience and skillbuilding include 1) equivalency experiential hours to onsite introductory clinical practice skills, 2) the virtual reality simulation system uses interactive dialogue with natural language processing, and is designed for history taking, evaluation of physical examination, including recognition of visual findings and heart and lung sounds, and ordering laband imaging tests, 3)the virtual reality simulation system includes a practice modality that includes built-in feedback, .4) ability to create experiential learning for geographically unavailable specialty sites and settings (i.e., Children's Hospital, clinics, burn unit), 5) medical nutrition mini games can be created within scenarios to reinforce concepts and skills, 6) utilization in a multitude of training sites various types of hospitals, clinics, community programs, sports nutrition, dietetics management, quality improvement and more, 7) versatility of virtual reality simulation experiential educational settings, type and pace of skill development and student levels of practice (Table 2).

It is designed to reproduce some aspect of the dietetic working environment using deliberate practice, reflection and feedback.It is currently being used in the public health, nursing, medical and surgical fields further making it ideal for dietetics and interdisciplinary healthprofessional training [1]. Its replay capability provides a unique tool for critiquing performance and measuring improvement. This cutting-edge technology has the potential for long-term sustainability with the ease of updating existing modules and creating new modules.

\section{VR SIMULATION PLATFORM}

This educational technique involves the development of virtual reality simulation with avatar-based training for healthcare personnel. The designing of a learning environment containing 3-D computer graphics need to fulfill some basic usability criteria characterizing common virtual reality environments and can be divided into four basic steps: 1) the geometry andappearance of virtual models, 2) their import to the virtual reality toolkit, 3) the modeling of their behavior and 4) the virtual environment visualization in a virtual reality facility [9].

Development includes creating digitally generated virtual clinical simulation avatars and modules scenarios. Depending upon available funding and potential partnerships there are several available vendors to develop virtual reality environments at a variety of costs. The learning platform is designed to develop and assess the clinical decision making skills for and by the dietetics student. It has a case learning platform, which provides a systemic approach to curriculum development, consists of the training platform and a supporting Case Authoring System (CAS). The functional components of the CAS (Table 3), including verification and validation of the platform,are integral to the conceptual design specifications and development of thelearning platform.

The evaluation produces discrete data, including qualitative analysis of platform usability and reliability, subject-matter expert evaluation of content and validity of curricula delivery, and quantitative analysis of the platform's learning effectiveness.A VR system usually includes four major elements: a computer of at least $500 \mathrm{MHz}$ with an advanced graphics card, a software program with the virtual environment, a tracking device that tells the computer where the user is looking based on head or body movement and an image display system such as a large high-resolution digital display or a head-mounted display (HMD) [9].

\section{The Role of the RD Educator during Virtual Reality Simulation}

Fundamental to the success of VR simulation relies on upfront commitment and designation of ample RD faculty time and resources for content development, writing modules, scenarios and script testing, debriefing, evaluation

Table 2. Potential new areas to use virtual reality simulation in education in dietetics

\begin{tabular}{|l|l|l|}
\hline \multicolumn{1}{|c|}{ Educational Setting } & \multicolumn{1}{|c|}{ Goal Skills to Learn } & \multicolumn{1}{c|}{ Student Level } \\
\hline Children's Hospital/clinic & Interdisciplinary communication & Undergraduate DPD \\
\hline SNAP-Ed \& Food Trust & Client Interviewing & Future Undergraduate degree program - NDA \\
\hline Olympics (sports Nutrition) & Client Counseling & Sports Nutrition Certification \\
\hline Private practice & Coding and Billing & Dietetic Internship program \\
\hline Food Service Systems & Designing a new hospital kitchen & RD Continuing Education program \\
\hline Adult Hospital medical/surgical specialties & Nutrition-focused Physical Exam & Future Graduate degree program for Entry-level RDN \\
\hline Adult Hospital Intensive Care Unit & Troubleshooting nutrition support complications & Onsite Master's Degree program \\
\hline Eating Disorders Unit & $\begin{array}{l}\text { Identify \& Treat Malnutrition and Refeeding } \\
\text { Syndrome }\end{array}$ & Online Master's Degree program \\
\hline
\end{tabular}


Table 3. Case authoring system.

\begin{tabular}{|l|l|}
\hline \multicolumn{1}{|c|}{ CAS Component } & \multicolumn{1}{c|}{ Description } \\
\hline Simulation Engine & $\begin{array}{l}\text { This is the core of the system. Cases are simulated in real-time in a virtual 3-D environment.The realistic environment } \\
\text { encourages student engagement, while performance is being measured and logged. }\end{array}$ \\
\hline Case Authoring Tool (CAT) & $\begin{array}{l}\text { The CAT enables the creation of instructional content via the incorporation of simulation assets (simulated patients, } \\
\text { medical environments, equipment, and healthcare personnel) to define the learner's situation. Learning objectives are } \\
\text { defined through the creation of a series of learner tasks that must be performed successfully to complete the } \\
\text { case.Finally, the creation of success metrics and scoring for each task allows the simulation engine to provide a score } \\
\text { for the student.Different scoring metrics can be entered for different levels of competencies, which allows a wide } \\
\text { variety of students to use the same case. }\end{array}$ \\
\hline 3-D Scene Designer & The tool allows developers to create and incorporate new assets. \\
\hline User Interface Editor & Enables developers to create custom user interface elements to facilitate intuitive control of the simulation. \\
\hline Conversation Designer & $\begin{array}{l}\text { The tool designs of how conversations will progress between healthcare personnel and patients.These conversations are } \\
\text { used both to provide the student with information and to test his communication skills. }\end{array}$ \\
\hline Physiology \& Condition Editor & $\begin{array}{l}\text { The editor allows for the rapid creation or modification of physiology modules for the physiology simulation } \\
\text { engine.These modules can define the functionality of body parts, body systems, medicines, or diseases. }\end{array}$ \\
\hline
\end{tabular}

Table 4. Role of the faculty RD during in VR simulation.

\begin{tabular}{|c|c|}
\hline Virtual Reality Simulation Development & $\begin{array}{l}\text { - Develops Curriculum } \\
\begin{array}{cl}\circ & \text { Writes learning objectives } \\
\circ & \text { Writes content for modules, script for avatars, scenarios } \\
\circ & \text { Provides design for physical environment } \\
\circ & \text { Customizes material for undergraduate, DI, graduate programs } \\
& \text { Collects and prepares linked resources and supporting material }\end{array} \\
\text { - Prepare training material and scenarios for facilitators/instructors }\end{array}$ \\
\hline Virtual Reality Simulation Testing & $\begin{array}{ll}\text { - } & \text { Test simulation modules, script scenarios with facilitators and instructors } \\
\text { - } & \text { Revise modules } \\
\text { - } & \text { Develop competency and skill testing tools } \\
\text { - } & \text { Develop student orientation to VR simulation } \\
\text { - } & \text { Determine how VR simulation will be blended into the curriculum and course } \\
\text { - } & \text { Develop Debriefing sessions post simulation }\end{array}$ \\
\hline \multicolumn{2}{|l|}{ Virtual Reality Simulation Debriefing } \\
\hline Virtual Reality Simulation Evaluation & \\
\hline
\end{tabular}

and simulation revision (Table 4).The actual cost implications, in terms of simple facility cost, average around $\$ 1000$ per day per student, which does not include costs, such as lost work hours, salary, subsistence, etc. [10].

\section{VIRTUAL REALITY SIMULATION PEDAGOGY}

In order for transformative learning to occur, learning must take place in a safe, open and trusting environment
[12]. Often the frantic situations of life or death crises in the hospital are not conducive to learning new skills. In order for transformation of to occur, student engagement must occur and the more that the student is engaged, the higher probability of success in the simulation module. Two important theoretical foundations to simulation learning are first, real or simulated experiences are simple catalysts for learning and second, the learning does not take place until after the experience during the debriefing. 
VR simulation fosters a novel framework for offsite or distance learning and life-long education shifting the center of education fromphysical classroom to the network. Thereby, students canapproach knowledge from any place, even from their own home, having as much time as they really need to study the educational material and practice skills. In order to support and enhance learning through virtual environments, specific pedagogical methods should be applied. Such methods include but are not limited to: behaviorism, cognitivism constructivism and collaborative learning Fig. (1) [12].

VR simulation is designed to address two underserved areas. The first example is geographic constraint where many areas in the U.S. providing dietetic training (DPD, DI, graduate, continuing education) have limited access to pediatric medical facilities. A second example entails patient safety where virtual reality simulation is a safer teaching arena for a novice dietetics student to practice a nutritionfocused physical examination than a live patient in the hospital with heightened anxiety and distraction from bells, alarms and moaning patients.Simulation-based learning helps students link the classroom with clinical settings while affording safe practice of newly attained clinical skills

There are a number of technologies that can be used to create an even greater immersive experience such as purposeful games - technology enabled games that provide experience and meaningful consequences that continually drive the activity to a goal of purpose using dynamics of play. Virtual labs is where learners actively control LIVE equipment and applications via their browser offering handson experience (e.g., Toolwire LiveLabs for IT hardware or software); branching video simulations uses interactive conversations set in realistic situations where the learner's decisions have meaningful consequences that enhance learning (e.g., Toolwire, LearnScapes); single user virtual environments is where individuals can explore and interact in a simulated 3-D environment (e.g., Caspian) and virtual immersive environments is where learners are empowered, as avatars, to build relationships, collaborate on projects and engage in competition in a digital [13].

\section{EDUCATIONAL CONCEPTUAL FRAMEWORKAND OUTCOMES}

The conceptual framework used to guide this research is based on Ericsson's [14]. work on expertise. Ericsson's framework suggeststhat to acquire expert performance one must engage in deliberate practice activities that are clearly focused on improving some aspect of performance. Most students tend to improve performance with experience; however, Ericsson's theory states that experts are those individuals who continue to improve beyond the level needed to perform adequately and become recognized as experts in their domain. Although students are just beginning in their skill development the underpinnings of Ericsson's theory can help educators focus deliberate efforts to improve selected skills or tasks. During this process, students are instructed to improve certain aspects of their performance for a well-defined task, such as communicating to a health care provider regarding a patient's status. The student is then given immediate detailed feedback on their performance which they can reflect upon and continue to practice during subsequent training sessions. Simulation is one of the techniques that can be used to engage professionals in deliberate practice of skills and has the ability to improve performance in professionals that require deliberate, goaloriented, and structured practice [14].

The identified student competency-based module withspecific goals and objectives are those that typically cannot be achieved in a traditional classroom setting alone [15]. They may also include fundamental experience and competencies gained in practice settings. Overall goals are patient care and decision-making skills; interpersonal and communication skill development; problem-solving performance and critical thinking skill development. Some outcomes facilitated by VR simulation may include: 1) to perform a complete and accurate nutrition-focused physical exam, 2) to devise a detailed nutrition care plan and communicate it to the medical team and families, and 3) to accurately assess patient educational needs and provide nutrition instruction to families. Not only the skills and competencies observable and measurable but they also

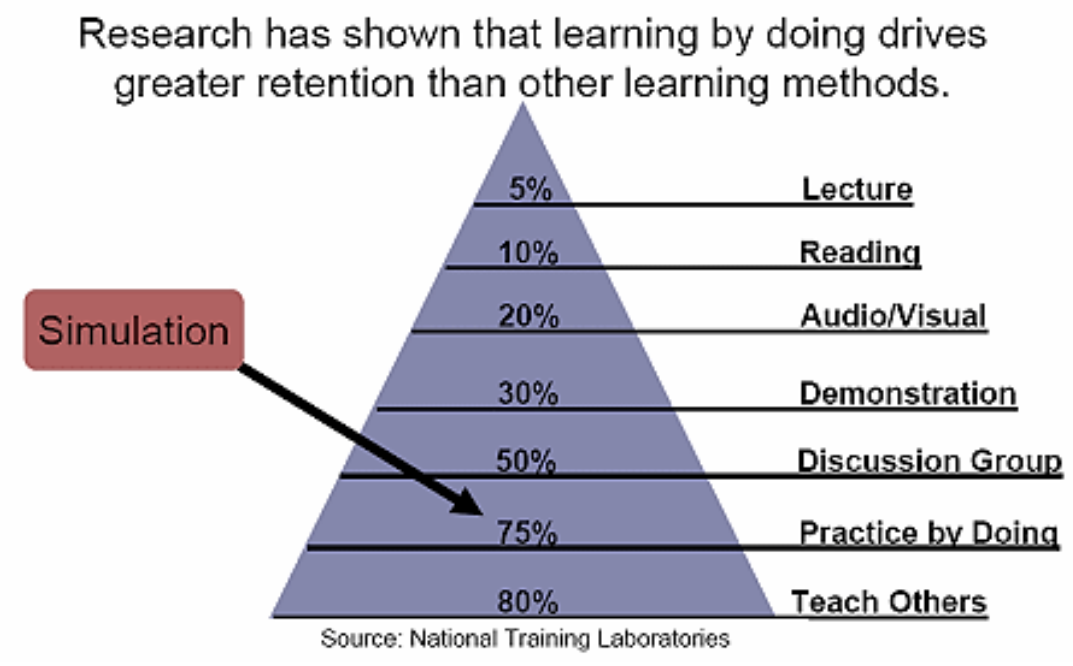

Fig. (1). Learning pyramid [12]. 
demonstrate outcomes from interdisciplinary health professional education and experience.

The modules and their scenarios and script are formatted to meet the standards, educational goals, objectives, outcomes andobjective structured assessment of clinical competencies for the Commission on Dietetic Registration(CDR)and Accreditation Council on Education for Nutrition and Dietetics (ACEND) supervised practice competencies [16-18].

\section{DESIGNING VIRTUAL REALITY SIMULATION WITH AVATARS DIETETIC LEARNING MODULES}

Writing a dietetic scenario involves starting with a template. The template incudes: 1) the admission date and brief description of the patient, 2) learning objectives, 3) fidelity (environment, props, equipment, medications, diagnostics, lab values, documentation forms, electronic health record, roles with guidelines, physician orders and student information needed prior to the scenario), 4) references, evidence-based practice guidelines, protocols, or algorithms used for the scenario, 5) simulation test plan categories and subcategories, scenario progression outline, 6) debriefing / guided reflection questions for the simulation and 7) designated complexity level. Other items include student assignments and support materials.

Virtual reality simulation modules include orientation to environment and avatars, built-in formative and summative evaluation tools, consisting of interactive multimedia simulation based performance assessment. As skills increase, the case study simulationsincrease in complexity (Fig.2). Each module includes avatars scripted in various scenarios to demonstrate skills and competencies as a (virtual) student dietitian interacting with a patient, family members and health professionals simulated in a virtual hospital environment.The VP's visual appearances are designed to represent various features of decubiti, malnutrition, vitamin deficiencies, edema, skin lesions or anorexia nervosa for a physical assessment.The instructor RD avatar demonstrates examination techniques while describing details that is followed by a separate avatar-driven performance isdirected and operated by the student and involves a nutrition-focused physical exam is conducted on the virtual patient to include percussion palpitation, and visual inspection of the VP's mucosa, skin, hair, eyes, lips, tongue, gums, fingernails, feet and any wounds.The data for the medical-surgical casebased modules are located in the Electronic Health record (EHR) software (Fig.3) which must be successfully extracted by the student.Web-based nutrition references, nutritional and medical formulas, calculations, and flow sheets appear in a 'pop-up' reference format and drop down menu selection. Input Hardware for the VR simulation and the virtual environment (VE) consists of macromedia flash and avatar animations to create interactive animated simulations.Voice/sound recognition is used to either to interact with agents within the simulation (e.g., VPs) or to manipulate objects in the simulation (e.g., information), Voice interaction to increase the level of immersion for the user.

A built-in electronic health record system (EHR) serves as an interdisciplinary repository for health information, orders and documentation for data collection and documentation and various scenarios will be created for the student RD to collect data from various hospital staff and make decisions from their collected data, resources and development of a nutrition care plan/consult/order writing (Fig.3). This type of experiential skill development is created, guided, supervised and designed to meet ACEND competencies for students in dietetic internships, medical nutrition therapy (MNT) classes, continuing RD education, online nutrition master's degree program, the future coordinated graduate program for entry level RDs and advanced practice dietetics [20]. The framework of the development of 8 evidence-based pediatric medical nutrition modules utilizes the nutrition care process [21].

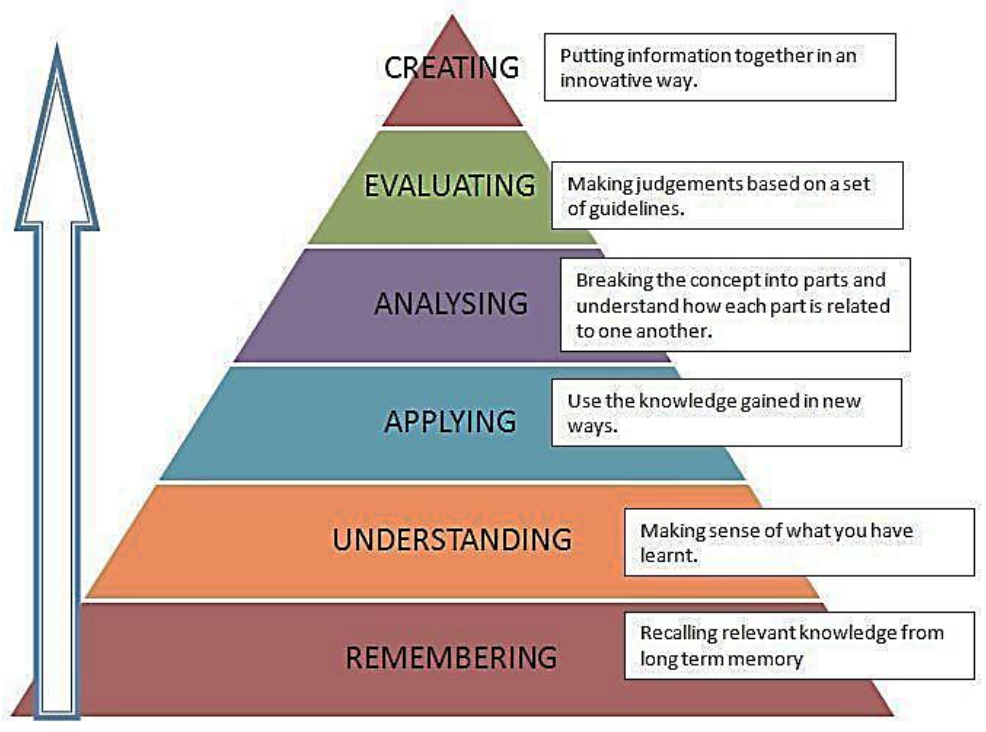

Fig. (2). Bloom's taxonomy of learning [19].. 


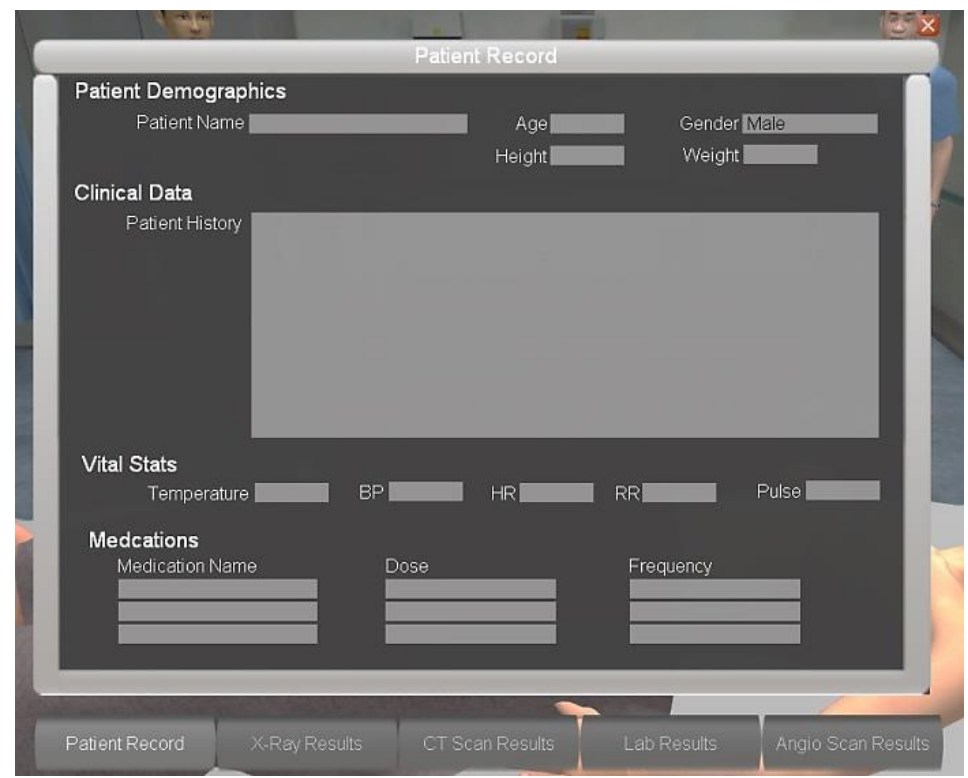

Fig. (3). Simulated electronic health record (Source: BreakAway Ltd., 11/25,/2013).

There are basically 4 steps to execution of the clinical nutrition VR simulation modules: pre-briefing, during scenario, debriefing and evaluation and revision. The purpose of pre-briefing is to explain the purpose of VR simulation, review the learning objectives, and review student and instructorexpectations, set the ground rules for the experience, review concepts related to the topic (prebriefing questions/assignments/activities) and calm fears. The importance of the first step sets the stage for the learning experience, provides hints for setting up the simulation environment to be conducive to learning, orients students to space and equipment, clarifies course outcomes, environment, avatar roles and expectations, establishes the fiction premise with students, attends to physical care and comfort, and conveys the commitment of respect for the students and understanding their perspective.

The simulation process involves maintaining an engaging context for learning, clarifying debriefing objectives, roles and expectations, helping students cope with and learn in a limited dietetic realism context and set the tone regarding dietetic realism. Debriefing is prepared in a room separate from active simulation environment. It is important for the room to be comfortable, private and intimate. Seating depends on the number of students debriefing and location of the facilitator as in or out of the circle. Debriefing is a structured process starting with a reactions step (how did you feel?), followed by the analysis step (what worked? what did not work? what would you done differently?) including a summary step (what were the 3 most important clinical factors?) and ending with the evaluation/revision step. The evaluation step is used to enhance student understanding, integrate content from different areas, translate content into action, increase comfort level in the clinical setting and interact with an interdisciplinary healthcare team.

\section{THE DEBRIEFING PROCESS}

Debriefing refers to the concept of reflection on an event or activity and subsequent analysis is the cornerstone of the experiential learning experience situations [22]. High student engagement is a hallmark of strong debriefings because it leads to deeper levels of learning and increases the likelihood of transfer to the clinical setting. Gibbs [23] describes the experiential learning cycle four phases: planning for action, carrying out action, reflection on action, and relating what happens back to theory.

Debriefing in simulation-based learning experiences is a crucial step in clarifying and consolidating insights and lessons from simulations. The Debriefing Assessment for Simulation in Healthcare(DASH) evaluates the strategies and techniques used to conduct debriefings by examining concrete behaviors. It is based on evidence and theory about how people learn and change in experiential contexts [24]. The DASH is designed to allow assessment of debriefings from a variety of disciplines and courses, varying numbers of participants, a wide range of educational objectives, and various physical and time constraints. Debriefing domains consist of cognitive, technical behavioral and perceptual questions. The seven elements to debriefing to be used in group format include the following: 1) debriefer, 2) students to debrief, 3) a learning experience (simulation scenario), 4) the impact of the learning experience (simulation scenario), 5) recollection, 6) report and 7) time [23]. The advantages and disadvantages of using validated debriefing questionnaires must be weighed when selecting debriefing tools [22].

Successful debriefing uses observable actions and outcomes as the basis for inquiry and discussion, reveals own reasoning, uses non-verbal techniques to facilitate discussion, uses video replay and review, recognizes and manages the upset participant, identifies and describes performance gaps, explores the basis of the performance gap and helps close performance gaps through discussion and teaching. In order for the instructor to provide an open, nonjudgmental safe environment for feedback, it is important to not personalize the debriefing, ask open-ended questions tailored to learning objectives and foster an inquisitive 
attitude. There are several perception scales available to use with students after VR simulation. A perception scale when teaching interdisciplinary skills is important to measure collaborative efforts [25]. Other important perception measures include the comparison of different teaching methods, perceived professional competence and autonomy, perceived need for professional cooperation, perceptions of actual cooperation and resource sharing within and across professions and understanding the value and contributions of other professions.

\section{INTEGRATING VIRTUAL REALITY SIMULATION WITH AVATARS INTO THE DIETETIC CURRICULUM}

Implementation of VR simulation into a dietetics course curriculum involves four steps: 1) pre-briefing, 2) during scenario, 3) debriefing and 4) evaluation and revision. The curriculum implementation plan for the virtual reality simulation with avatars for experiential skill development consists of avatar-led, inter-health discipline professional experiences and clinical nutrition case modules Fig. (4). Curricular placement may include a medical nutrition terminology course or as dietetic intern orientation clinical supervised practice.
These modules are developed, reviewed, tested and added to the virtual hospital environments. Modules include content, descriptions of scenarios and case presentations, skill demonstration, instructions for imitation, feedback on competency, problem-solving, critical thinking and technique, practice and grading. Dietetic students work through one or more avatars that they control to act on their behalf as a student clinical dietitian to manipulate and practice newly acquired information and skills. Scenarios are sequenced in a logical array that allow for the accumulation of new skills with increasing levels of difficulty from novice to mastery. New skills are evaluated at every level through student demonstration Fig. (5).

The evaluation stage and involves a multi-mix method to evaluate the implementation of VR simulation modules and includes traditional pre and post-test evaluations, student and faculty evaluation and debriefing skills.Students and faculty assess the quality of the training and technology via competency rubrics and surveys. Post simulation technique and modules are evaluated with an after-action report (AAR) or improvement plan (IP) skills (Table 3).

Other areas where VR simulation has been introduced include continuing education (CE) for registered dietitians/ nutritionists. Patient Simulation: Putting Malnutrition

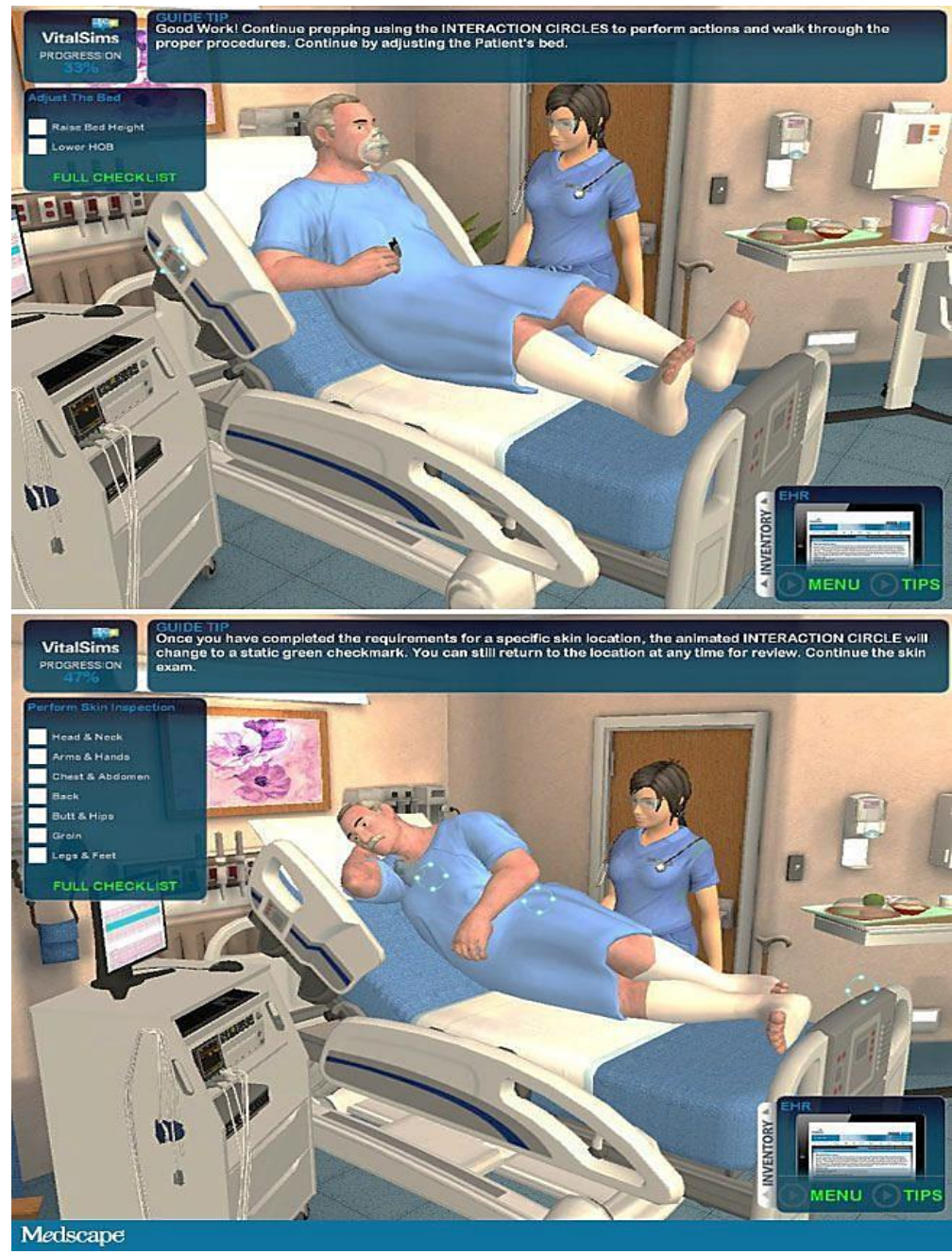

Fig. (4). Example of a hospitalized patient's VR room and patient and nurse avatars. 


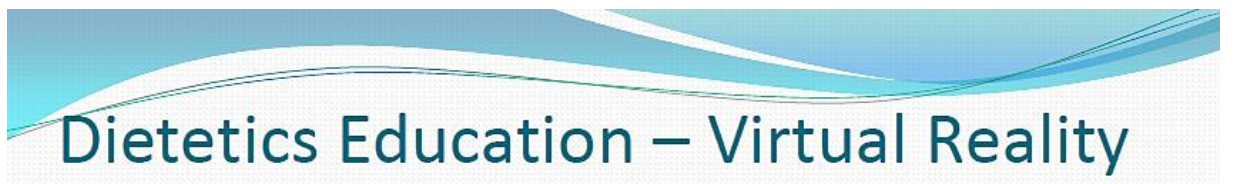

- Interview and Counseling Skills

- Virtual patients

- Diabetes mellitus

- Cardiovascular disease

- Renal disease

- Weight management
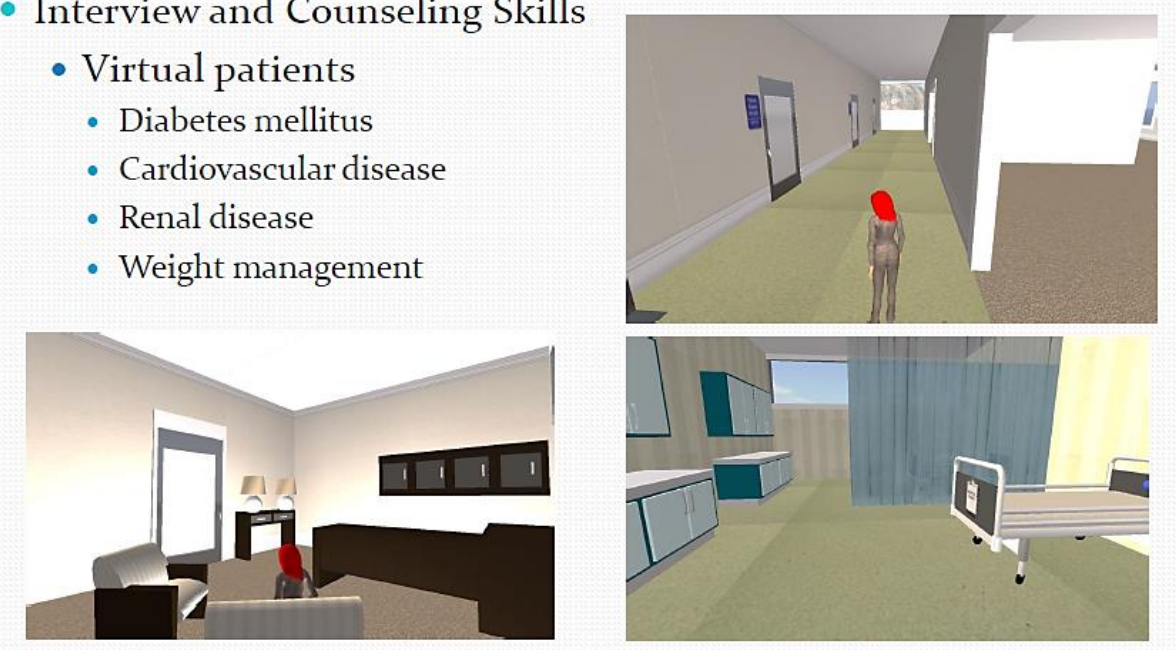

\section{Plan to Add Electronic Medical Records}

Fig. (5). Dietetics Education - Virtual Reality [2014 FNCE, Univ. of Kansas]..

Screening, Assessment, Diagnosis, and Intervention into Practice is an online self-study course available at http://anhi.org/abbott-learning-center [26]. In this simulation course, nurses, dietitians, and other health care team members have the opportunity to experience patient care through the eyes of a registered dietitian for an inpatient cardiology unit and learn how malnutrition diagnosis is made and how dietitians can use the Nutrition Care Process to assist the health care team in improving patients' nutrition status (Fig. 6). A recently admitted patient has been referred for suspected malnutrition after heart surgery. Using the electronic medical record (EMR) and physical assessment simulations, the four steps of the Nutrition Care Process (Assessment, Diagnosis, Intervention, and Monitoring \& Evaluation) is completed while learning how to assess each of the malnutrition clinical characteristics in order to determine if a malnutrition diagnosis is appropriate. Throughout the simulation course, the Malnutrition Clinical Characteristics worksheet, based on the Academy of Nutrition and Dietetics (Academy) and American Society of Parenteral and Enteral Nutrition (A.S.P.E.N.) guidelines" is used [26].

Evaluation activities are driven by student learning objectives. There are specific themes for qualitative evaluations of students such as knowledge and skills acquisition, teamwork development, clinical reasoning/ critical thinking and self-awareness/confidence building. VR simulation program evaluation entails assessing the instructor/facilitator, quality of simulation experience, learner satisfaction for each scenario and reflecting how to address each area. Once the evaluation is conducted, the next step is to re-write scenarios per student feedback and experience, gain additional training on how to pre- and debrief (practice) and adjust VR simulation learner environments.
Assessment of student learning can utilize various tools such as standardized exams, Objective Structured Clinical Exams (OSCE), course exams, checklists and rating scales. Assessments may be conducted in a pre-/post-simulation format or comparison of different teaching methods.

\section{THE POTENTIAL OF VR SIMULATION IN DIETETICS}

Students practice their craft in scripted scenarios designed to challenge their clinical decision making, critical thinking, and teamwork. Simulation has many advantages over lecture-based education. Among the most important factors are: Interactivity and immediacy-making choices and immediately seeing the result of actions; Applying knowledge in context; Allowing time for reflection (thinking through their choices and patient outcomes) and Group learning (learning from peers and from facilitator) [25]. Advantages of learning on simulators instead of patients include: Learners experience the key elements of patient care in a manner that does not put lives at risk. The learner can experience common conditions, or those they may see once in their entire career. Learners practice their cognitive, psychomotor, and affective skills without placing patients at risk. Learners collaborate, working together in teams to achieve goals-similar to true clinical practice. Learners repeat the process until they achieve the required mastery of the concept. Learners experimenttrying alternate approaches to a problem or making intentional mistakes to practice error recovery. Learners reflecton the impact of their decisions and those of others on patient outcome. Facilitators standardize training opportunities (to make sure every learner is exposed to core content and the most critical rare situations). Facilitators track the successes and failures of learners and can benchmark their performance [25].The next 


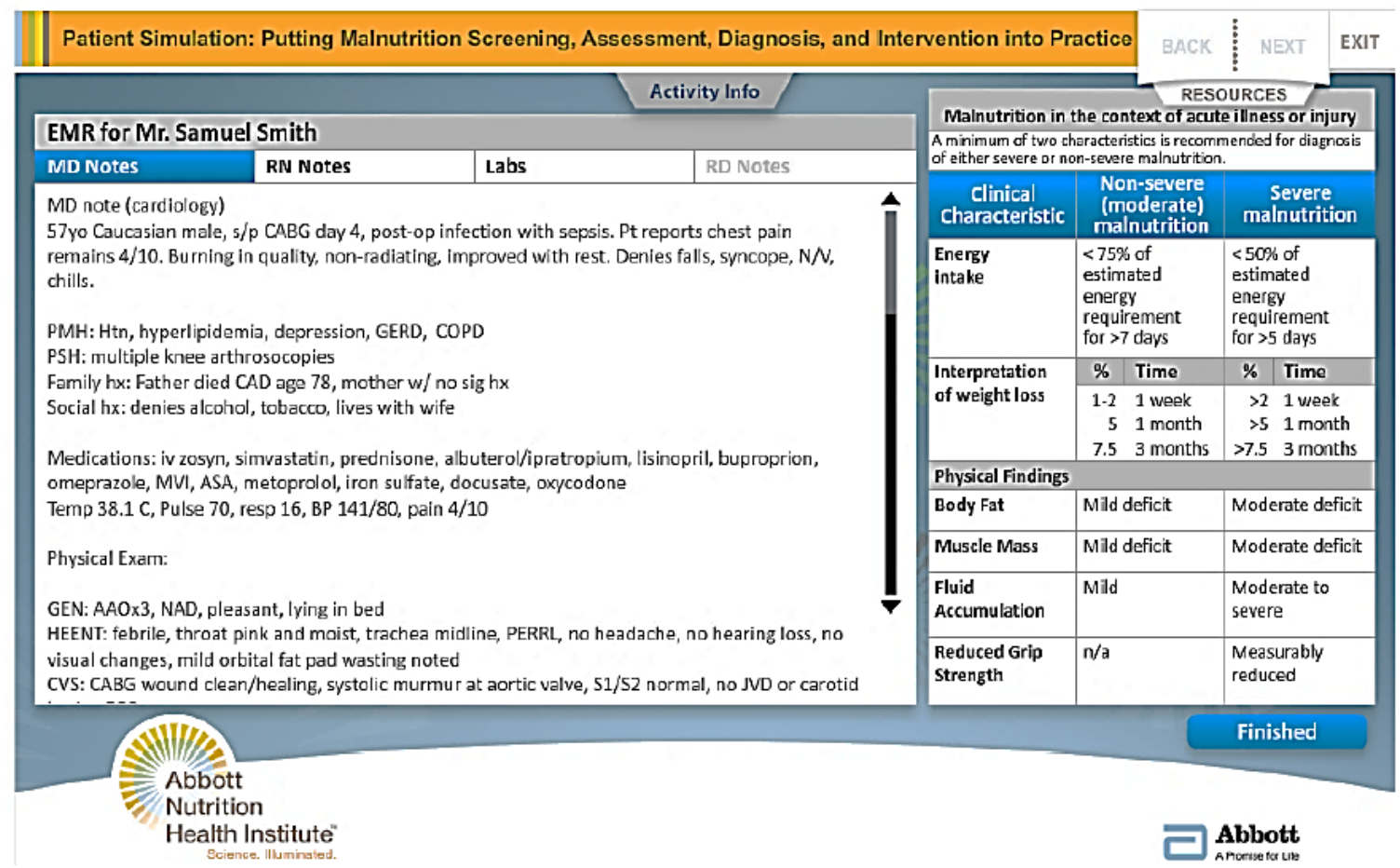

Fig. (6). Patient Simulation: Putting Malnutrition Screening, Assessment, Diagnosis, and Intervention into Practice [26].

frontier may be validating VR simulation and using VR simulation to conduct research. Just such examples have been seen in recent publications on 'Using Virtual Reality to Provide Nutritional Support to HIV+ Women' [27]., "'Alien Health Game": An Embodied Exergame to Instruct in Nutrition and MyPlate [28]. 'The virtual supermarket: An innovative research tool to study consumer food purchasing 'behavior' [29] and 'New Directions in the Use of Virtual Reality for Food Shopping: Marketing and Education Perspectives'[30].

\section{CONCLUDING CONSIDERATIONS AND REMARKS}

Virtual reality simulation technology has versatility and because it is web-based will be accessible to the dietetics profession at large. Using VR simulations allow students to experience clinical cases rarely seen in actual patient populations, have customized guidance and feedback, and offer more time for practice, repetition and reflection than currently possible. It permits flexible learning for students, enabling them to accrue hours of experience and competence. This virtual learning environment offers meaningful, on-demand, discovery-based learning of crucial health-care expertise in controlled settings in which student can practice and refine an array of dietetic skills, including critical thinking, decision-making and differential diagnostics in a specific dietetic context while experiencing clinical consequences safely. Computer-based case VR simulations ("virtual patients", VP) Fig. (5) are advocated as useful and reliable tools for teaching clinical skills and evaluating competence for dietetic students using a developed internet-based VP system in a simulated hospital environment designed both for practice and assessment.
Current thinking is that advanced skills development will rely heavily on simulators to provide experiential learning, but this training comes at a high cost in terms of trainee, trainer, and facility time. The VR simulation platform may be redesigned for other dietetic experiential settings such as a food service department, private practice or clinic, employee wellness center, and more. The avatars can be developed to represent other persona and professionals. Alternatively, other skills, behaviors and competencies can be demonstrated, practiced and tested within these new module scenarios and evolving learning requirements.
ABBREVIATIONS

$\mathrm{AAR}$
$\mathrm{ACE}$
$\mathrm{ACEND}=$ After Action Report
$\mathrm{CAS}=$ Accreditation Council on Education for
$\mathrm{CBT}=$ Case Authoring System
$\mathrm{CDR}=$ Computer-Based Training
$\mathrm{DASH}=$ Debriefing Assessment for Simulation in
$\mathrm{DI}=$ Dietetic Internship
$\mathrm{DPD}=$ Didactic Program in Dietetics
$\mathrm{EAL}=$ Evidence Analysis Library
$\mathrm{EHR}=$ Electronic Health Record
$\mathrm{IP}=$ Improvement Plan
$\mathrm{MNT}=$ Medical Nutrition Therapy




$\begin{array}{lll}\text { NCP } & =\text { Nutrition Care Process } \\ \text { PPT } & =\text { Part-Task Training } \\ \text { RD } & =\text { Registered Dietitian } \\ \text { VE } & =\text { Virtual Environment } \\ \text { VHC } & =\text { vHealthCare }{ }^{\mathrm{m}} \\ \text { VP } & =\text { Virtual Patients } \\ \text { VR } & =\text { Virtual Reality }\end{array}$

[12] Krathwohl DR. A revision of bloom's taxonomy: An overview. Theory Pract 2002; 41(4): 212-8.

[13] Online experiential learning: Helping individuals practice and perform. towards maturity www.towardsmaturity.org/practice 2013.

[14] Ericsson KA. Deliberate practice and the acquisition and maintenance of expert performance in medicine and related domains. Acad Med 2004; 79(10): S70-81.

[15] Youngblood P, Harter PM, Srivastava S, Moffett S, Heinrichs WL Dev P. Design, development, and evaluation of an online virtual emergency department for training trauma teams. Simul Healthc 2008; 3(3): 146-53.

[16] Accreditation council for education in nutrition and dietetics. academy of nutrition and dietetics acend accreditation standards for dietitian education programs leading to the rd credential. Version 1.04, Chicago, IL Updated July 31, 2013.

At the time of writing this manuscript the author and colleagues had submitted a proposal to the Academy of Nutrition and Dietetics, Foundation for a Simulation Grant in Dietetic Education.

\section{ACKNOWLEDGEMENTS}

Declared none.

\section{REFERENCES}

[1] Gaddis T. Virtual reality in the school. Virtual reality and Education Laboratory. East Carolina University. 1998.

[2] Society for Simulation in Healthcare. What is Simulation? http://ssih.org/about-simulation [Accessed: January 15, 2014].

[3] Winn W. A conceptual basis for educational applications of virtual reality. Technical Report TR 93-9. Available: www.hitl. washington.edu/publications/ r-93-9/1993.

[4] Damassa DA, Toby DS. Simulation technologies in higher education: uses, trends, and implications. Boulder, CO: EDUCAUSE Center for Applied Research, 2010, available from http://www.educause.edu/ecar

[5] Hudock SD. The application of educational technology to occupational safety and health training. Occup Med 1994; 9: 201-10.

[6] Salzman MC, Dede C, Loftin RB, et al. A model for understanding how virtual reality aids complex conceptual learning. Presence 1999; 8: 293-316.

[6] Davis D. Does CME work? An analysis of the effect of educational activities on physician performance or health care outcomes. Int $\mathbf{J}$ Psychiatry Med 1998; 28: 21-39.

[7] Raidl MA, Wood OB, Lehman JD, Evers WD. Computer-assisted instruction improves clinical reasoning skills of dietetic students. J Am Diet Assoc 1995; 95: 868-78.

[8] Aldrich C. Paradoxes of educational simulations: A new way to view a world that is not that tidy.' Train Develop 2006; 60(5): 4956.

[9] Masso JPM, Lopez PG. Model-based design and new user interfaces: current practices and opportunities. Proceedings of the First International Workshop on the Design Specification and Verification of Interactive Systems, 2003; 9: 245-57.

[10] Buelow R, Janet D, Matthew R, et al. Building interdisciplinary teamwork among allied health students through live clinical case simulations. J Allied Health 2008; 37(2): 109E-23E.

[11] Boulos M, Kamel N, Hetherington L, Wheeler S. Second Life: an overview of the potential of 3-D virtual worlds in medical and health education. Health Info Libraries J 2007; 24: 233-45.
[17] accreditation council for education in nutrition and dietetics. acend accreditation standards for didactic programs in nutrition \& dietetics leading to supervised practice. Version 1.04, Chicago, IL Updated July 31, 2013.

[18] Accreditation council for education in nutrition and dietetics. ACEND accreditation standards for internship programs in nutrition \& dietetics leading to the rd credential. Version 1.04 , Chicago, IL, July 31, 2013.

[19] Noble T. Integrating the revised bloom's taxonomy with multiple intelligences: A planning tool for curriculum differentiation. Teach Coll Rec 2004; 106: 193.

[20] Academy of Nutrition and Dietetics. Visioning Report- Final 9/5/2012. Chicago, IL

[21] Academy of Nutrition and Dietetics. Nutrition care process and model part I: the 2008 update. J Acad Nutr Diet 2008; 7: 1113-7.

[22] Fanning RM, Gaba DM. The role of debriefing in simulation-based learning. Simul Healthc 2007; 2(2): 115-25.

[23] Flanagan B. Debriefing: Theory and techniques. In: Riley RH, ed. Manual of Simulation in Healthcare. NewYork NY: Oxford University Press 2008; pp. 155-70.

[24] Debriefing Assessment for Simulation in Healthcare (DASH) Student Version $\odot$ Copyright, Center for Medical Simulation, www.harvardmedsim.org, 2011 plus the Dash Instructor Version, DASH Rater's Handbook and DASH Rater Version.

[25] Taekman JM, Shelley K. Virtual environments in healthcare: immersion, disruption, and flow. Telemedicine and Advanced Technology Research Center 118. Taekman and Shelley www.anesthesiaclinics.com (W81XWH-06-1-0720) and the Agency for Healthcare Research and Quality (U18 HS016653-01).

[26] Patient simulation: putting malnutrition screening, assessment, diagnosis, and intervention into practice. Abbott Laboratories 90396/February 2014 www.ANHI.org, Available at http://anhi.org/ abbott-learning-center

[27] Brown S, Nunez D, Blake E. Using virtual reality to provide nutritional support to HIV+ women. Presence 2005; 319-23.

[28] Johnson-Glenberg MC, Hekler EB. 'Alien health game: an embodied exergame to instruct in nutrition and my plate. Games Health J 2013; 2(6): 354-61.

[29] Waterlander WE, Scarpa M, Lentz D, Steenhuis IHM. The virtual supermarket: An innovative research tool to study consumer food purchasing behavior. BMC Public Health 2011; 11: 589-99.

[30] Ruppert B. New directions in the use of virtual reality for food shopping: marketing and education perspectives. J Diab Sci Technol 2011; 5(2): 315-8.

This is an open access article licensed under the terms of the Creative Commons Attribution Non-Commercial License (http://creativecommons.org/licenses/by-nc/3.0/) which permits unrestricted, non-commercial use, distribution and reproduction in any medium, provided the work is properly cited. 